\title{
Endoglin (CD105) is not a specific selection marker for endothelial cells in human islets of Langerhans
}

\author{
C. P. D. Wheeler-Jones - C. E. Clarkin - C. E. Farrar • \\ P. Dhadda • P. Chagastelles • N. Nardi • P. M. Jones
}

Received: 18 August 2012 / Accepted: 13 September 2012 / Published online: 28 October 2012

(C) Springer-Verlag Berlin Heidelberg 2012

Keywords CD $105 \cdot$ Endoglin $\cdot$ Human islet $\cdot$ Mesenchymal stromal cells $\cdot$ Microvascular endothelial cells

\begin{abstract}
Abbreviations
EC Endothelial cell

MEC Microvascular endothelial cell

MSC Mesenchymal stromal cell

TGF- $\beta$ Transforming growth factor- $\beta$
\end{abstract}

To the Editor: We read with interest the recent report by Favaro et al [1] suggesting that microvascular endothelial cells (MECs) isolated from human islets of Langerhans could be protected from hyperglycaemia-induced apoptosis by gastrointestinal peptides. In this study, as in several previous studies [2-5], the MECs were expanded in vitro from a population that had been isolated from dispersed

C. P. D. Wheeler-Jones • C. E. Farrar

Comparative Biomedical Sciences, The Royal Veterinary College,

London, UK

\section{E. Clarkin}

Centre for Biological Sciences, University of Southampton,

Southampton, UK

P. Dhadda $\cdot$ P. M. Jones $(\bowtie)$

Diabetes Research Group, Division of Diabetes and Nutritional

Sciences, School of Medicine, Kings College London,

Guy's Campus, London Bridge,

London SE1 1UL, UK

e-mail: peter.jones@kcl.ac.uk

\section{P. Chagastelles}

Universidade Federal do Rio Grande do Sul,

Porto Alegre, Brazil

N. Nardi

Universidade Luterana do Brasil,

Canoas, Brazil human islet cells using anti-CD105 immunobeads. CD105 (also known as endoglin) is a membrane glycoprotein that acts with transforming growth factor (TGF)- $\beta$ receptors as an auxiliary binding protein for members of the TGF- $\beta$ family, including activin, TGF- $\beta 1 / \beta 3$ and bone morphogenic proteins. Macro- and microvascular endothelial cells (ECs) are certainly CD105-positive, but this accessory receptor is also highly expressed by a range of other cell types including bone marrow- and tissue-derived mesenchymal stromal cell (MSC)-like populations. In accordance with this, we have recently isolated from human islets, and expanded in vitro, a population of CD105-expressing cells that are clearly not MECs, but which share phenotypic characteristics with other cells that have been immuno-isolated on the basis of CD105 expression and identified as islet MECs for in vitro studies [1-5].

Our cell population was isolated and expanded essentially as described for MSCs [6]. Briefly, human islets (obtained from the King's College London Human Islet Isolation Unit, with appropriate ethics approval) were dissociated by incubation in $0.02 \%$ (wt/vol.) EDTA solution with trituration. Cells were resuspended in Dulbecco's Modified Eagle's Medium supplemented with L-glutamine $(2 \mathrm{mM})$, penicillin $(100 \mathrm{U} / \mathrm{ml})$, streptomycin $(172 \mu \mathrm{mol} / \mathrm{l})$ and FCS $(10 \%$ vol./ vol.), seeded in six-well tissue culture dishes and incubated at $37^{\circ} \mathrm{C}$ in a humidified atmosphere containing $5 \% / 95 \%$ $\mathrm{CO}_{2} /$ air. The medium was changed after $24 \mathrm{~h}$, with removal of non-adherent cells, and when adherent cultures reached confluence, they were trypsinised and subcultured into tissue culture flasks. These cells are likely to be a heterogeneous population of adherent islet stromal cells, including fibroblasts, myofibroblasts and pericytes, as well as MSCs with differentiation potential. In accordance with this, the cells possessed many of the attributes associated with MSCs $[6,7]$, rather than MECs, as shown in Fig. 1. They did not exhibit the typical cobble-stone morphology of monolayer ECs (Fig. 1a-c), but had a fibroblast-like spindle 


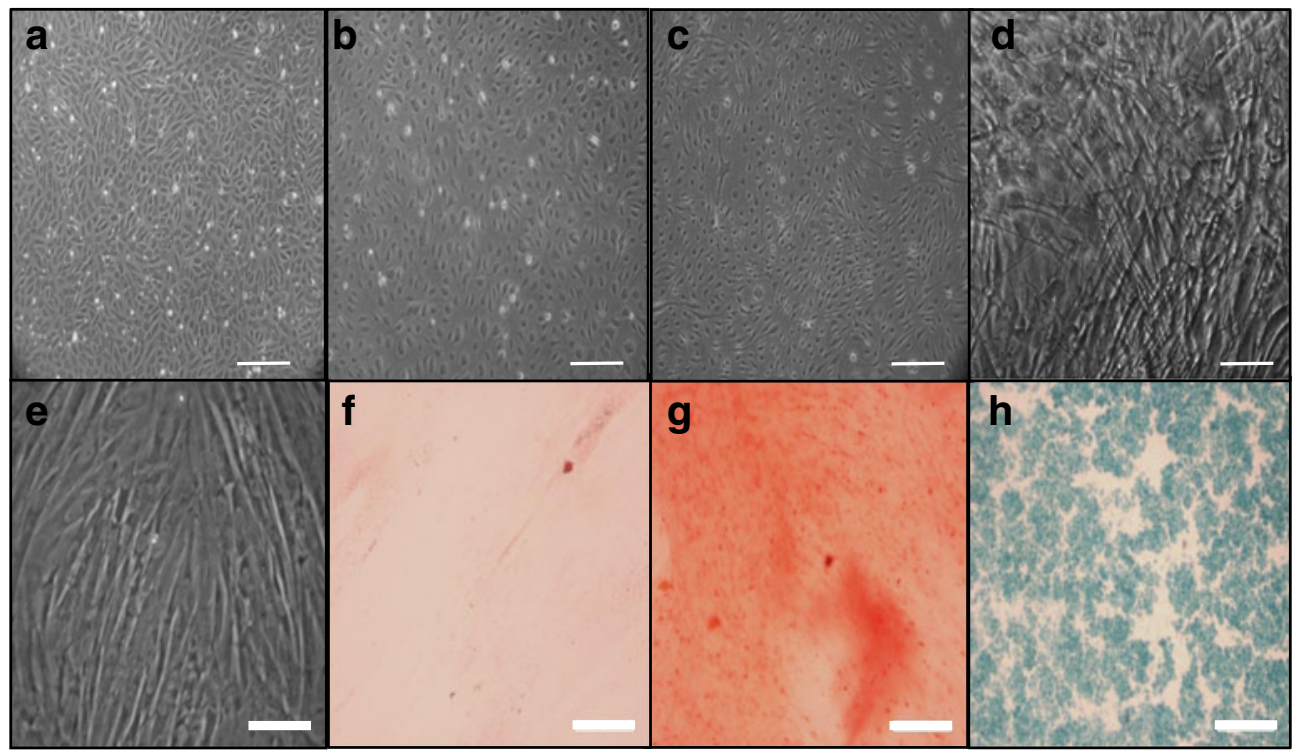

Fig. 1 Phenotypic characteristics of endoglin-expressing ECs and non-MECs. (a-c) Non-islet EC populations demonstrating typical morphology in adherent monolayer culture. (a) Human umbilical vein ECs (macrovascular, isolated as described in Garonna et al [8]); (b) human lung MECs (Lonza, Basel, Switzerland), isolated using CD31 immunobeads; (c) mouse lung MECs, isolated using ICAM-2 antibody (AbD Serotec, Oxford, UK) and immunobeads (Dynabeads; Invitrogen, Paisley, UK). (d) For comparison, CD105-positive human islet-

morphology similar to MSCs (Fig. 1d). Cells within this population were multipotent and differentiated in vitro along adipogenic (Fig. 1f), osteogenic (Fig. 1g) and chondrogenic (Fig. 1h) lineages, assessed by positive oil red $\mathrm{O}$, alizarin red and alcian blue staining, respectively. Flow cytometry demonstrated that they expressed cell surface antigens typically associated with MSCs, including CD105, CD13, CD44, CD73 and CD90, but did not express cell surface antigens characteristic of MECs, including CD31, CD34, CD69, CD117 and vascular endothelial growth factor receptor-2 [7]. Our cells were capable of expansion in standard EC culture medium supplemented with EC growth factors and, in common with both macro- and microvascular ECs [8], they formed capillary-like tubes when maintained on Matrigel (BD Biosciences, Oxford, UK; not shown), as has been reported previously for cell populations isolated from human islets on the basis of CD105 expression [2]. Despite this, the morphology, cell surface marker/receptor expression and multipotency of our cell isolates are not consistent with an islet MEC phenotype.

It is well documented that CD105 is not an EC-specific marker in other tissues, and we here extend this to human islets of Langerhans. Our demonstration that human islets contain more than one population of CD105-expressing cells suggests that isolation strategies based solely on CD105 expression are unlikely to generate a purified islet MEC population. The initial immuno-isolated population derived MSCs were characterised by a fibroblastic, elongated morphology. Scale bars $100 \mu \mathrm{m}$. (e-h) Differentiation potential of islet-derived, CD105-positive MSCs. Islet MSCs (e) were maintained in defined media [6] for 28 days, and differentiation along adipogenic (f), osteogenic (g) and chondrogenic (h) lineages was evaluated by positive oil red $\mathrm{O}$ staining of lipid droplets, alizarin red staining of mineral deposition and alcian blue staining of GAG deposition within cell micromasses, respectively. Scale bars $25 \mu \mathrm{m}$

will contain MECs because they express CD105, but during expansion in culture the MECs may be outgrown by a CD105-expressing MSC population. The precise identity of the CD105-positive, non-MEC population that we have isolated and expanded from human islets is uncertain, but our observations suggest that cells isolated and characterised solely on the basis of CD105 expression (or of the expression of CD146, another general stromal cell marker) are likely to comprise a heterogeneous population that may be unsuitable for functional studies of islet MECs.

Acknowledgements We are grateful to G.-C. Huang and S. Amiel (Diabetes and Nutritional Sciences, King's College London) for supplying the human islets used in our studies.

Funding This work was supported by the BHF (CPDW-J, grant PG/ 07/063/23289), a Diabetes UK/Diabetes Foundation Fellowship (CEC, CPDW-J, PMJ, grant 08/0003675), a Wellcome Trust Veterinary Training Fellowship (CEF) and an MRC Postgraduate Training Award (PD).

Contribution statement CPDW-J and PMJ were responsible for the conception of the letter. CEC, CEF, PD, NN and PC generated and analysed data. All authors contributed to the drafting and revision of the letter, and approved the final version.

Duality of interest The authors declare that there is no duality of interest associated with this manuscript. 


\section{References}

1. Favaro E, Granata R, Miceli I et al (2012) The ghrelin gene products and exendin-4 promote survival of human pancreatic islet endothelial cells in hyperglycaemic conditions, through phosphoinositide 3-kinase/Akt, extracellular signal-related kinase (ERK)1/2 and cAMP/protein kinase A (PKA) signalling pathways. Diabetologia 55:1058-1070

2. Favaro E, Bottelli A, Lozanoska-Ochser B et al (2005) Primary and immortalised human pancreatic islet endothelial cells: phenotypic and immunological characterisation. Diabetologia 48:2552-2562

3. Zanone MM, Favaro E, Doublier S et al (2005) Expression of nephrin by human pancreatic islet endothelial cells. Diabetologia 48:1789-1797

4. Zanone MM, Favaro E, Ferioli E et al (2007) Human pancreatic islet endothelial cells express coxsackievirus and adenovirus receptor and are activated by coxsackie B virus infection. FASEB J 21:3308-3017

5. Favaro E, Miceli I, Bussolati B et al (2008) Hyperglycemia induces apoptosis of human pancreatic islet endothelial cells: effects of pravastatin on the Akt survival pathway. Am J Pathol 173:442-450

6. da Silva ML, Chagastelles PC, Nardi NB (2006) Mesenchymal stem cells reside in virtually all post-natal organs and tissues. J Cell Sci 119:2204-2213

7. Dominici M, Le Blanc K, Mueller I et al (2006) Minimal criteria for defining multipotent mesenchymal stromal cells. The International Society for Cellular Therapy position statement. Cytotherapy 8:315-317

8. Garonna E, Botham KM, Birdsey GM, Randi AM, Gonzalez-Perez RR, Wheeler-Jones CP (2011) Vascular endothelial growth factor receptor-2 couples cyclo-oxygenase-2 with pro-angiogenic actions of leptin on human endothelial cells. PLoS One 6:e18823 